\title{
Cigarros Eletrônicos: 0 que Sabemos? Estudo sobre a Composição do Vapor e Danos à Saúde, o Papel na Redução de Danos e no Tratamento da Dependência de Nicotina
}

https://doi.org/10.32635/2176-9745.RBC.2018v64n4.210

\author{
E-Cigarettes: How Much do we Know about Them? A Study on the Composition of the Vapour and Harmful Effects \\ on Health and the Role they Play in Reducing Harm and Treating Nicotine Addiction \\ Cigarrillos Electrónicos: ¿Qué Sabemos? Estudio sobre la Composición del Vapor Y los Daños a la Salud, el Papel \\ en la Reducción de Daños y en el Tratamiento de la Dependencia a la Nicotina
}

\author{
Instituto Nacional de Câncer José Alencar Gomes da Silva. Rio de Janeiro: INCA; 2016. 120p. \\ ISBN 978-85-7318-287-3 (versão impressa) \\ ISBN 978-85-7318-288-0 (versão eletrônica)
}

Aline de Mesquita Carvalho'

O tabagismo é considerando um grave problema de saúde pública. Uma doença - dependência da droga nicotina - que é também fator de risco para inúmeras outras e se destacam diversos tipos de câncer, doenças cardiovasculares e pulmonares. É o principal fator isolado evitável de adoecimento e morte, responsável por mais de sete milhōes de mortes a cada ano segundo a Organização Mundial da Saúde (OMS) ${ }^{1,2}$.

Diversos são os produtos derivados de tabaco consumidos ao redor do mundo, mas o cigarro industrializado representou um marco importante na expansão da epidemia do tabaco, sendo até hoje largamente o mais consumido ${ }^{3,4}$.

As açóes de controle do tabaco ganharam muita força no Brasil a partir da década de 1980 e integram uma rede mundial onde se destaca a elaboração e implementação do primeiro tratado mundial de saúde pública, a ConvençãoQuadro para o Controle do Tabaco da OMS, da qual o Brasil é signatário. Tais iniciativas orquestradas mundialmente têm contribuído para a redução da epidemia tabagística, redução essa que foi expressiva no Brasil. Entretanto, os desafios ainda são muitos e diários. Um desses desafios foi a entrada no mercado mundial dos chamados dispositivos eletrônicos para fumar (DEF), também conhecidos como cigarros eletrônicos, que trouxe para os países, governos, comunidade científica e saúde pública a necessidade de produzir e buscar evidências científicas para subsidiar as decisóes relacionadas à regulaçáo de tais produtos 5 .

Nesse cenário, foi publicado, pelo Instituto Nacional de Câncer José Alencar Gomes da Silva (INCA), o livro Cigarros Eletrônicos: O que sabemos? Estudo sobre a composição do vapor e danos à saúde, o papel na redução de danos e no tratamento da dependência de nicotina. Trata-se do trabalho resultante da revisão ampla de artigos científicos e outras publicaçóes, realizado pela médica Stella Regina Martins, da Universidade de São Paulo, fruto de uma parceria firmada entre a Organizaçáo Pan-Americana da Saúde (Opas/OMS), a Agência Nacional de Vigilância Sanitária (Anvisa) e o INCA. Seu objetivo foi, com essa ampla revisão, fornecer um material baseado em evidência científica para a Coordenação de Prevenção e Vigilância (Conprev) do INCA e a Gerência-Geral de Produtos Derivados do Tabaco (GGTAB) da Anvisa.

O livro se organiza em nove capítulos seguidos das Consideraçôes Finais sobre o tema. Os cinco primeiros capítulos fornecem um rico material que permite a contextualização do cenário do tabagismo e açôes para o seu controle no Brasil e no mundo, onde surgem os cigarros eletrônicos. São eles: Epidemiologia do tabagismo no Brasil e no mundo; Políticas Públicas no Brasil e no mundo; Fisiopatologia da dependência de nicotina; Doenças tabaco-relacionadas; e Custo do tabagismo no mundo e no Brasil.

${ }^{1}$ Instituto Nacional de Câncer José Alencar Gomes de Alencar (INCA). Rio de Janeiro (RJ), Brasil. Orcid iD: https://orcid.org/0000-0002-2066-3755

Endereço para correspondência: Aline de Mesquita Carvalho. Rua Marques de Pombal, 125, 50 andar - Centro. Rio de Janeiro (RJ), Brasil. CEP $20230-240$. E-mail: alinem@inca.gov.br 
O capítulo seguinte, Cigarros Eletrônicos, entra diretamente no tema em questão, iniciando com a descrição e composição do produto, destinado a entregar a nicotina, provinda da folha do tabaco, na forma de aerossol, sendo alguns comercializados também sem nicotina. Há um número vasto e variado de modelos; mas, em geral, são aparelhos mecânico-eletrônicos alimentados por bateria de lítio. Seu interior é composto por um espaço para a inserção do cartucho ou refil, onde fica armazenada a nicotina líquida, disponível em diferentes concentraçôes. $\mathrm{O}$ atomizador é responsável por aquecer e vaporizar a nicotina.

A autora passa entáo a descrever os diversos modelos de DEF disponíveis no mercado, bem como a composição dos vapores que são absorvidos pelos usuários desses produtos. Destaca a presença de dois solventes, glicerol e propilenoglicol que, quando aquecidos a altas temperaturas, geram compostos carbonílicos de baixo peso molecular, como o formaldeído, o acetaldeído, a acroleína e a acetona, substâncias classificadas como citotóxicas, carcinogênicas, irritantes, causadoras do enfisema pulmonar e de dermatite. São apresentados, em maiores detalhes, essa composição, tabelas e gráficos comparativos com os cigarros comuns, além da descrição de danos à saúde.

Em seguida, ainda no mesmo capítulo, são descritos os casos e riscos de intoxicação pelos cartuchos ou refis de nicotina em adultos, bebês e crianças, sinais e sintomas de intoxicação por ingestão de nicotina, e finaliza com os casos de explosão do dispositivo já documentados.

O capítulo seguinte discorre, de forma detalhada, com ilustrações fundamentais como complementação ao conteúdo apresentado, os aspectos relacionados à comercialização e o consumo dos DEF. É composto pelos tópicos: propaganda - repetição das estratégias usadas pela indústria do tabaco para a comercialização dos cigarros eletrônicos; prevalência (com dados mundiais sobre o consumo); mensagens de advertências (que já vêm sendo adotadas por países onde o consumo desses produtos é liberado); e interesse financeiro da indústria do tabaco no mercado dos cigarros eletrônicos.

O conceito de redução de danos é abordado no capítulo 8 com a conceituação inicial proposta em saúde pública, no contexto de uso de drogas psicoativas. Em seguida, a autora traz o uso desse conceito aplicado ao tabagismo, traçando inclusive um paralelo entre o que pensa a saúde pública por meio de políticas de controle do tabagismo e o que é proposto pelas indústrias do tabaco e farmacêuticas.

O capítulo 9 fala especificamente do tratamento da dependência da nicotina, discorrendo sobre o que há de evidências sobre o tema até o momento, e sobre pesquisas e evidências sobre o possível uso do cigarro eletrônico para esse fim.

Em suas consideraçôes finais, a autora aponta para o grande número de perguntas sem resposta sobre o efeito dos DEF sobre a saúde do indivíduo, a saúde coletiva e as políticas de controle do tabaco que têm sido tão bem-sucedidas. Reconhece a entrada do cigarro eletrônico no cenário do tabagismo como um desafio a ser enfrentado e recomenda a comunicação e fornecimento para a população de informaçôes sobre o tema; o monitoramento do uso do produto por meio de pesquisas diversas e abrangentes; acompanhamento em relaçáo a novos estudos e evidências que venham surgindo, devendo ser organizados para subsidiar órgãos competentes sobre o tema, ressaltando a baixa qualidade metodológica da maioria dos estudos publicados até o momento, e a necessidade de maiores investigaçóes; e finaliza que, pelo princípio de precaução e por prevenção, "não se pode recomendar a regulação dos DEF como um produto derivado do tabaco".

Essa obra tem sido de fundamental importância para subsidiar as discussōes sobre os DEF no país. A autora é uma especialista no tratamento do tabagismo e no controle do tabaco, e estudiosa dedicada. Vem se debruçando nos últimos anos sobre o tema cigarros eletrônicos, tendo participado de diversos fóruns científicos e consultivos. Esse perfil certamente se reflete na publicação em questão. O livro é bem organizado, claro e bastante abrangente em termos de material pesquisado. Além disso, a autora teve a preocupação de inserir a questão central em um contexto mais amplo, o que facilita e embasa as consideraçóes sobre o tema. O leitor consegue percorrer esse caminho lógico e chegar junto com a autora às conclusões e recomendaçóes propostas. $\mathrm{O}$ livro, portanto, cumpriu seu objetivo inicial e certamente é uma ótima indicaçáo para todos que desejam conhecer ou se aprofundar sobre o assunto.

\section{REFERÊNCIAS}

1. GBD 2016 Risk Factors Collaborators. WHO report on the global tobacco epidemic, 2017: monitoring tobacco use and prevention policies. Geneva: WHO;2017.

2. GBD 2016 Risk Factors Collaborators. Global, regional, and national comparative risk assessment of 84 behavioural, environmental and occupational, and metabolic risks or clusters of risks, 1990-2016: a systematic analysis for the Global Burden of Disease Study 2016. Lancet. 2017;390(10100):1345-1422. doi: https://doi.org/10.1016/S01406736(17)32366-8. 
3. Instituto Brasileiro de Geografia e Estatística. Pesquisa nacional de saúde. Rio de Janeiro: IBGE; 2014.

4. Asma S, Mackay J, Song SY, Zhao L, Morton J, Palipudi KM, et al. The GATS atlas: global adult tobacco survey. Atlanta, GA: CDC Foundation; 2015.

5. Ministério da Saúde (BR), Secretaria de Vigilância em Saúde, Departamento de Vigilância de Doenças e Agravos não Transmissíveis e Promoção da Saúde. Saúde Brasil 2017: uma análise da situaçáo de saúde e os desafios para o alcance dos objetivos de desenvolvimento sustentável. Brasília: Ministério da Saúde; 2018. 